\title{
Flow analysis of a set of ornamental chimney caps designed by Antoni Gaudí
}

\author{
Albert Samper ${ }^{1 \dagger}$, Jordi Iglesias ${ }^{2 \dagger}$, Blas Herrera ${ }^{3}$ and Jordi Pallares ${ }^{2 *}$ (]
}

\begin{abstract}
We analyzed theoretically and experimentally the performance of the 19 different ornamental caps of the individual chimneys located on the terrace of Palau Güell (Barcelona, Spain) designed by Antoni Gaudí. This set of chimney caps has wide range of external geometries and different number and shapes of openings. Models of the chimney caps were obtained using photogrammetry and 3D printing. Wind tunnel measurements of the pressure inside the stack pipe connected to the cap were performed for different external and stack flow velocities. Two distinct orientations of the external flow with respect to the chimneys were considered. We derived a simple theoretical model, based on the potential flow theory, to relate the non-dimensional pressure reduction in the stack (chimney draft) with the ratio between the external and stack flow velocities. It has been found that the behavior of the chimneys caps predicted by this model is in agreement with the measurements. It has been found that the performance of the chimneys depends mainly on the number of supports of the conical cover of the cap and it is essentially independent on the shape of the cap and on the number and geometry of the openings located on the cap. These conclusions obtained for this particular set of chimneys can be useful for the design of caps for ornamental or general use.
\end{abstract}

Keywords: Antoni Gaudí, Palau Güell, Chimney caps, Chimney draft, Ornamental chimney, Fluid mechanics, Wind tunnel

\section{Introduction}

Chimneys have been widely used to conduct combustion and flue gases and other contaminants from animal housing and domestic and industrial sources to the atmosphere. They are also an essential part of many natural ventilation systems [1,2]. In these systems the outlet flow rate is governed by three effects: (1) the difference in air density between the inside and the outside of the building due to temperature and/or composition (humidity) of the air, (2) the aerodynamic effects due to the wind flowing around the building and (3) the location and the geometry of the ventilation elements.

Chimney caps, fitted at the top of the chimney, usually are mainly designed to protect the stack conduit from

\footnotetext{
*Correspondence: jordi.pallares@urv.cat

${ }^{\dagger}$ Albert Samper and Jordi Iglesias contributed equally to this work

2 Departament d'Enginyeria Mecànica, Universitat Rovira i Virgili,

43007 Tarragona, Spain

Full list of author information is available at the end of the article
}

rain and to inhibit downdraft. In some cases, their design is also oriented to improve the draft. Examples are stationary $[3,4]$ and mobile suction caps which are oriented by the wind to locate the exit aperture windward [5] and rooftop turbine ventilators [6,7]. Besides the practical advantages of the chimney caps, these devices have been used for ornamental purposes since Roman times [8]. In the Middle Ages ornamental chimney caps were progressively sophisticated to indicate and show richness and power. The culmination of chimneys with visible ornamental caps has been a way to emphasize that the building was equipped with heating and consequently the inhabitants were in a good social position $[9,10]$. Two well-known examples are the chimneys of the Hampton Court Palace (Molesey, UK), designed by Christopher Wren in 1514, and the chimneys of the Palau Güell (Barcelona, Spain), designed by Antoni Gaudí in 1890 .

The determination and analysis of the flow characteristics of full ventilation systems or individual

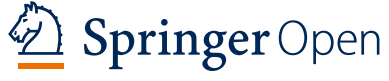

(c) The Author(s) 2020. This article is licensed under a Creative Commons Attribution 4.0 International License, which permits use, sharing adaptation, distribution and reproduction in any medium or format, as long as you give appropriate credit to the original author(s) and the source, provide a link to the Creative Commons licence, and indicate if changes were made. The images or other third party material in this article are included in the article's Creative Commons licence, unless indicated otherwise in a credit line to the material. If material is not included in the article's Creative Commons licence and your intended use is not permitted by statutory regulation or exceeds the permitted use, you will need to obtain permission directly from the copyright holder. To view a copy of this licence, visit http://creativeco mmons.org/licenses/by/4.0/. The Creative Commons Public Domain Dedication waiver (http://creativecommons.org/publicdomain/ zero/1.0/) applies to the data made available in this article, unless otherwise stated in a credit line to the data. 
ventilation elements are usually carried out using wind tunnels and/or through numerical simulations. Wind tunnel measurements, using scale models, are convenient to evaluate the wind induced ventilation inside buildings [11-13] and the performance of individual ventilation elements under well controlled flow conditions [14-16]. Although these experiments are relatively costly, they provide local reliable data using pressure and velocity probes and spatial flow information using Particle Image Velocimetry [17] and flow visualization techniques. On the other hand, numerical simulations using computational fluid dynamics (CFD) tools give detailed flow information but usually face the large Reynolds number of these kind of flows. Numerical predictions of scaled situations require relatively large computational resources and sometimes depend on the specific turbulence model used [18]. The application of experimental fluid mechanics techniques [19] and CFD to analyze the flow behavior in relevant situations related with the understanding and preservation of art and heritage is quite recent, as pointed out in [20]. Numerical simulations of the flow inside historic buildings and museums can be used to predict the airflow and its potential effects on the art works, as the temperature or humidity uniformity or the particle deposition rates. This information can be useful to help in the conservation management. Examples of application of CFD tools to predict airflows in heritage buildings and historical sites can be found in [21-28].

The objective of this study is the determination, using wind tunnel measurements, of the structural elements of ornamental chimney caps of the Palau Güell that contribute positively to the draft of the chimney and of the elements that may produce malfunction and downdrafts. This information is relevant, firstly, to understand which are the designs created by Antoni Gaudí that produce a more efficient draft and, secondly, because it can be used for the design of chimney caps for ornamental and general use. Figure 1a, b show pictures of the roof and of some individual chimneys, respectively. The interested reader can find more details about Palau Güell, a World Heritage building since 1984 , in $[29,30]$.

The paper is organized as follows. The wind tunnel setup and measurements are described in "Experimental setup and measurements" section. "General characteristics of the chimneys" section reports the main characteristics of the 19 chimney caps considered and "Model and discussion" section describes the analysis of the measurements and the development, and comparison with measurements, of a simplified theoretical model based on the potential flow theory. In "Conclusions" section the main conclusions of the paper are outlined.



Fig. 1 Pictures of the roof of Palau Güell (Barcelona, Spain). a General views of the roof. $\mathbf{b}$ Pictures of individual chimney cap. The pictures of the general view of the roof are used with permission of the Diputació de Barcelona

\section{Experimental setup and measurements}

Figure 2 shows a sketch of the main elements and equipment used to perform the measurements. In the experiments, an external constant and uniform flow was supplied by an open-jet wind tunnel with a square nozzle exit area of $1.5 \mathrm{~m} \times 1.5 \mathrm{~m}$. The wind tunnel generates a parallelepipedic experimentation volume of $2 \mathrm{~m}$ along the streamwise direction and a cross sectional area of $0.8 \mathrm{~m} \times 0.8 \mathrm{~m}$. In this volume the uniformity of the velocity is within $5 \%$ and the maximum turbulence level is about $1 \%$. The tunnel has external dimensions $2.4 \mathrm{~m} \times 2.4 \mathrm{~m} \times 3.8 \mathrm{~m}$. The main elements are (in the direction of the flow) fans, plenums, flow straighteners, and conditioning elements, a contraction and test section. The flow is impelled by four fans of $7.5 \mathrm{~kW}$ each, with a diameter of $1 \mathrm{~m}$ and placed in a $2.24 \mathrm{~m} \times 2.24 \mathrm{~m}$ matrix. The fans feed a $1 \mathrm{~m}$ long plenum chambers with a safety screen at the end. A honeycomb and two grids are placed windward to reduce the flow turbulence intensity and increase the flow uniformity. The open jet exits into the test section from a nozzle, with a contraction of ratio 2.23 and a length of $1 \mathrm{~m}$, to increase the flow speed. More information about the flow characterization and details of the tunnel can be found in [31]. 


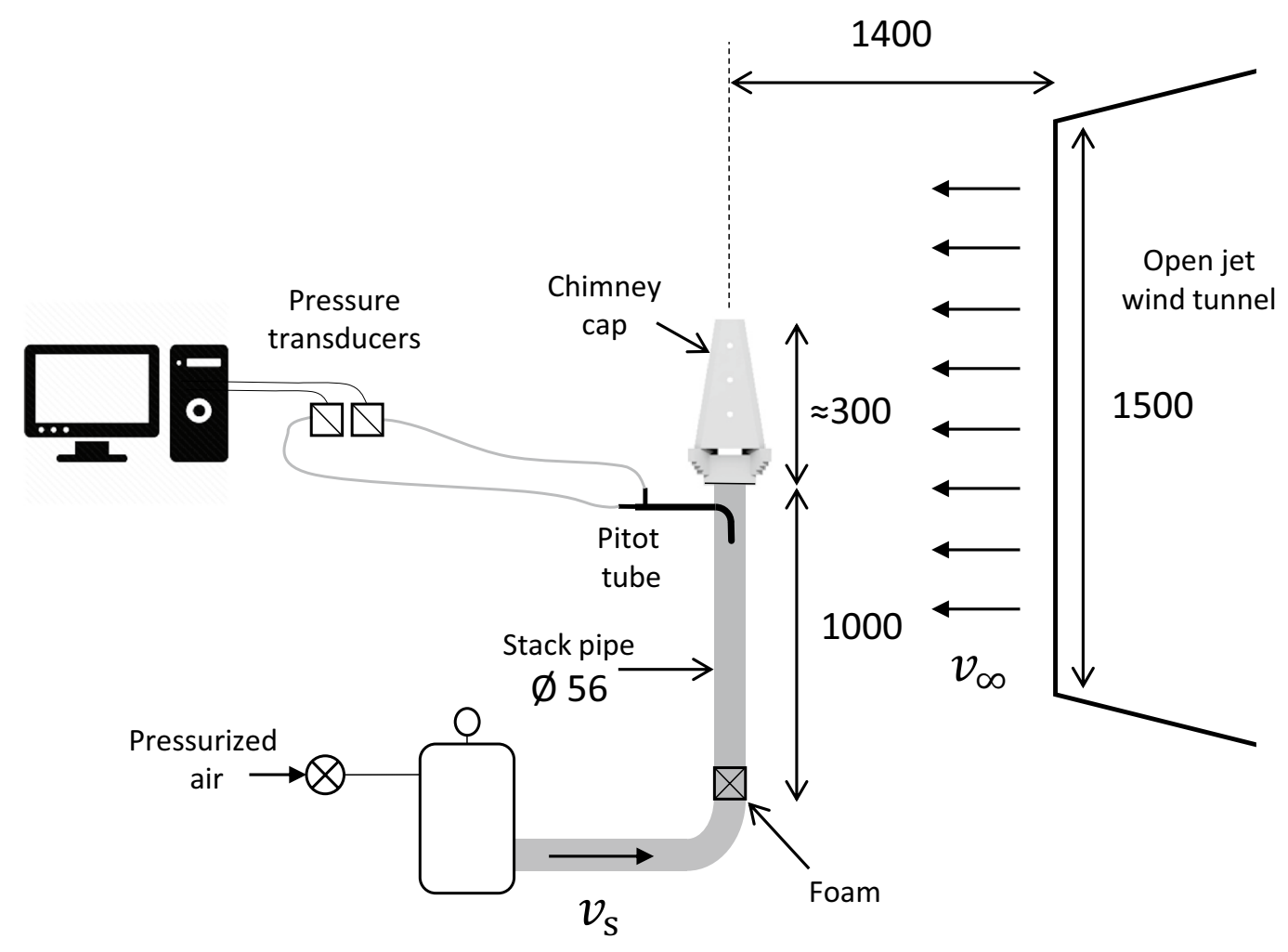

Fig. 2 Sketch of the experimental setup. Dimensions are millimeters

The STL (standard tessellation language) files of each model were obtained from 30 pictures (Canon EOS 5D Mark IV) of the real chimney. These pictures capture all the surfaces of the chimney and they were processed using the software Agisoft PhotoScan Professional to obtain the photogrammetry of the models, which was imported with Autocad to generate the final STL files. Models of the 19 chimney caps were printed at 1:5 scale using a 3D printer SigmaX with PLA (Polylactic Acid) filament of diameter $2.85 \mathrm{~mm}$.

Figure 3 shows frontal and top views of the models analyzed. In this figure they appear grouped, and the rationale behind this classification is explained in detail in next section. The vertical dimension of the models ranged from $270 \mathrm{~mm}$ of chimney \#18 to $355 \mathrm{~mm}$ of chimney \#2. They were installed, in the experimentation area, with their vertical axis perpendicular to the external flow velocity at a distance of $1400 \mathrm{~mm}$ from the wind tunnel nozzle and they were connected to the PVC (polyvinyl chloride) stack pipe with an inner diameter of $56 \mathrm{~mm}$ (see Fig. 2). Compressed air was supplied to the stack pipe from a tank to obtain a controlled air flow rate. A cylindrical foam was installed inside the stack pipe to produce a pressure drop and to minimize the effect of the bend in the flow downstream to the chimney cap. The velocity at the center axis of the stack pipe was measured with an accuracy of $0.1 \%$ with a calibrated $8 \mathrm{~mm}$ pitot tube located at one pipe diameter below the base of the cap (see Fig. 2). It was connected to two calibrated Setra C239 differential pressure transducers and the signals were sampled at $1 \mathrm{kHz}$ and recorded, typically, during $10 \mathrm{~s}$ in a computer. One of the transducers measured the difference between the atmospheric pressure and the total (dynamic plus static) pressure of the pitot tube and the other one measured the difference between the atmospheric pressure and the static pressure of the pitot tube. With this arrangement the velocity and the static pressure inside the tube can be determined simultaneously.

The stack velocities $\left(v_{s}\right)$ were typically varied between 0.4 and $3.6 \mathrm{~m} / \mathrm{s}$ and the external flow velocities were within the range $1.5 \mathrm{~m} / \mathrm{s} \leq v_{\infty} \leq 9.1 \mathrm{~m} / \mathrm{s}$. The corresponding ranges of Reynolds numbers based on these velocities and the inner diameter $(d)$ of the stack pipe 
a
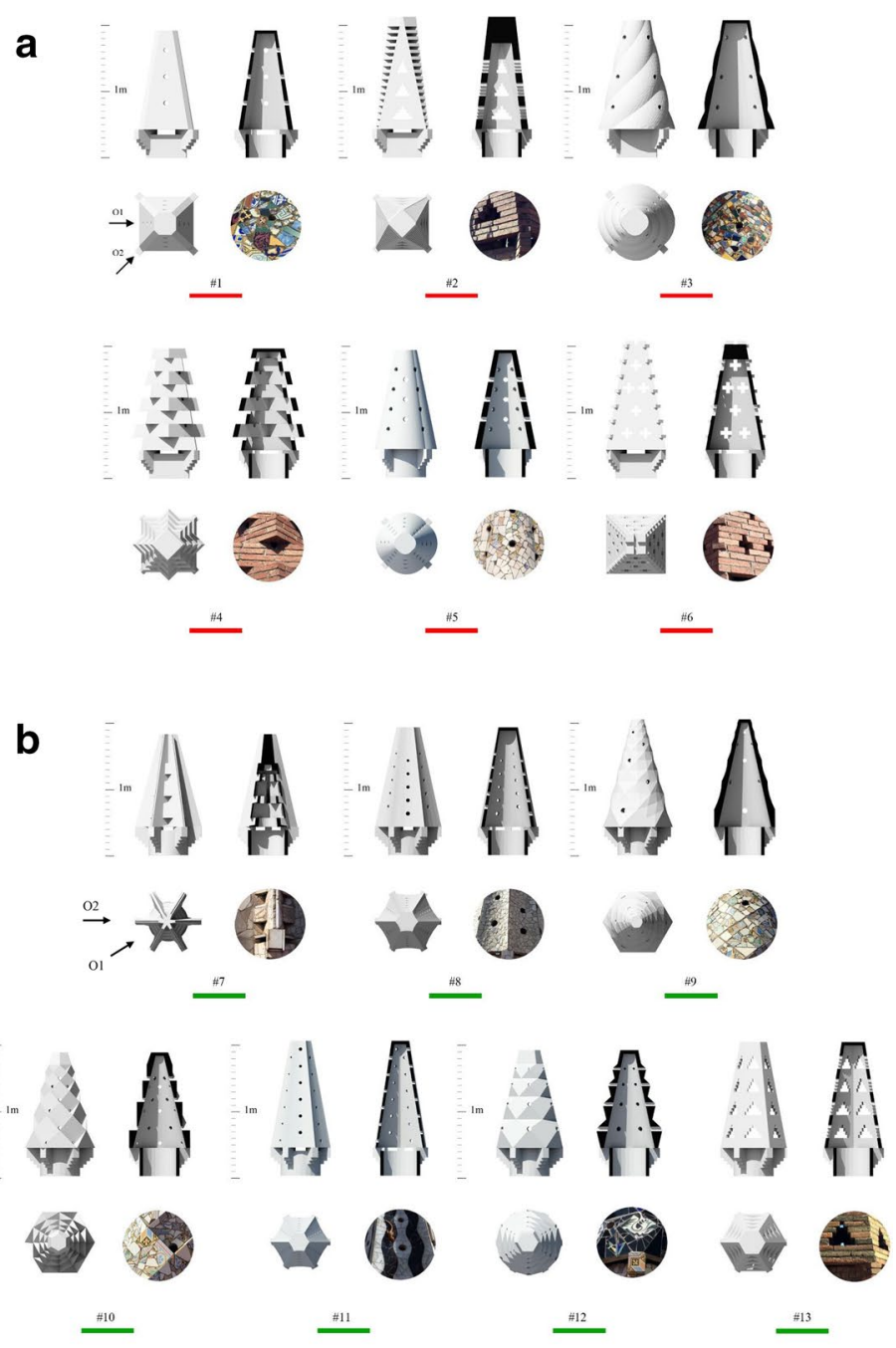

C
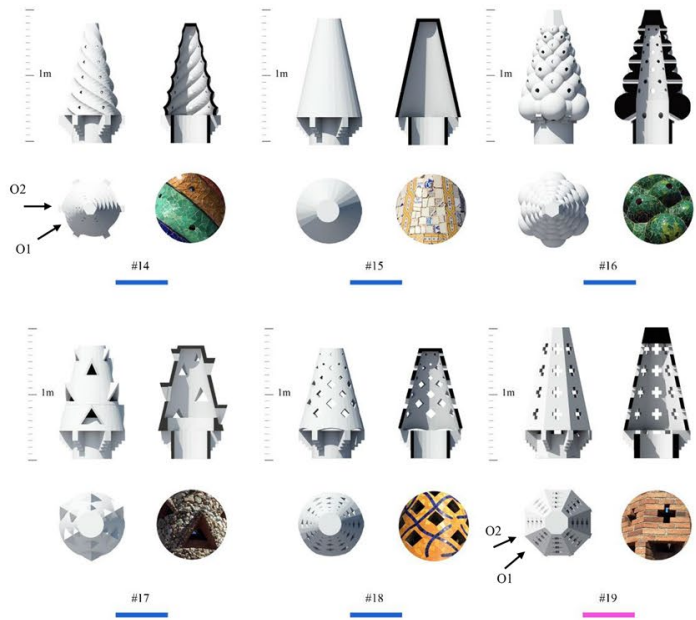

Fig. 3 Frontal and top views of the 19 individual chimneys. Vertical cuts are also shown to reveal the internal geometry of the chimneys. The two different orientations of the external flow (O1 and $\mathrm{O} 2$ ) are indicated near the top views of chimneys \#1, \#7, \#14 and \#19. A picture of the finish cover for each individual chimney is included to easily identify the location of the chimney on the roof shown in Fig. 1. Chimneys are distributed in panels (a), (b) and (c) according to their performance 
and the height $(h)$ of the chimney cap $\left(R e_{d}=v_{s} d / v\right.$ and $\left.R e_{h}=v_{\infty} h / v\right)$ were $1.5 \cdot 10^{3} \leq R e_{d} \leq 1.3 \cdot 10^{4}$ and $3.0 \cdot 10^{4}$ $\leq R e_{h} \leq 1.8 \cdot 10^{5}$, respectively. Considering the Reynolds number similarity (i.e. equal Reynolds numbers) between the experiments and the full-scale real chimney caps, the experiments performed with 1:5 scale models correspond to maximum full-scale wind velocities of $1.82 \mathrm{~m} / \mathrm{s}$ and maximum full-scale stack velocities of $0.72 \mathrm{~m} / \mathrm{s}$. Examples of the use of scale models in wind tunnel experiments for ventilation analyses similar to those considered in this study are reported in [11-16].

For each of the 19 models, measurements were carried out for two different orientations of the chimney cap with respect to the direction of the external flow. These two orientations correspond to wind velocities directed towards two vertical symmetry planes of the bases of the chimneys as discussed below. Figure 3 indicates with arrows the two different orientations, denoted as $\mathrm{O} 1$ and $\mathrm{O} 2$, of the external flow velocity near the top view of chimneys \#1, \#7, \#14 and \#19.

\section{General characteristics of the chimneys}

The set considered in this study is constituted by 19 individual chimneys (see Fig. 1). Besides the different materials used to cover the external part, the chimneys have a relatively large variation of geometries, different structural elements and, probably most important, different number and distribution of the openings along the external surface of the cap (see for example Fig. 1b). The caps and the openings are based on different geometrical shapes, as cylindrical, tronconical or prismatic columns and the culmination elements exhibit polyhedric, spherical, conical, cylindrical or helicoidal surfaces.

The two main parts of the chimney caps, common to all the models, are, from bottom to top: (1) a base, which is connected to the stack pipe, with a set of supports distributed symmetrically along the perimeter of the upper part and (2) a cover mounted over the supports. Figure 4 shows, as an example, three chimneys with the covers separated from their respective supports. There are three types of bases. Chimneys \#1 to \#4 and \#6 have bases with square cross section (see Fig. 3a). Chimneys \#7 to \#18 and chimney \#5 have bases of circular cross section (Fig. 3b, c) and chimney \#19 has a base with octagonal cross section (see Fig. 3c). It should be noted, irrespectively of the cross section of the outer part of the base, that all the bases of the chimneys have circular inner sections with the same diameter (see for example Fig. 4).

Figure 3 shows that bases of chimneys \#1 to \#6 have 4 vertical symmetry planes and 4 supports distributed along the diagonals of a square, while chimney \#7 to \#18 have 6 vertical symmetry planes and 6 supports

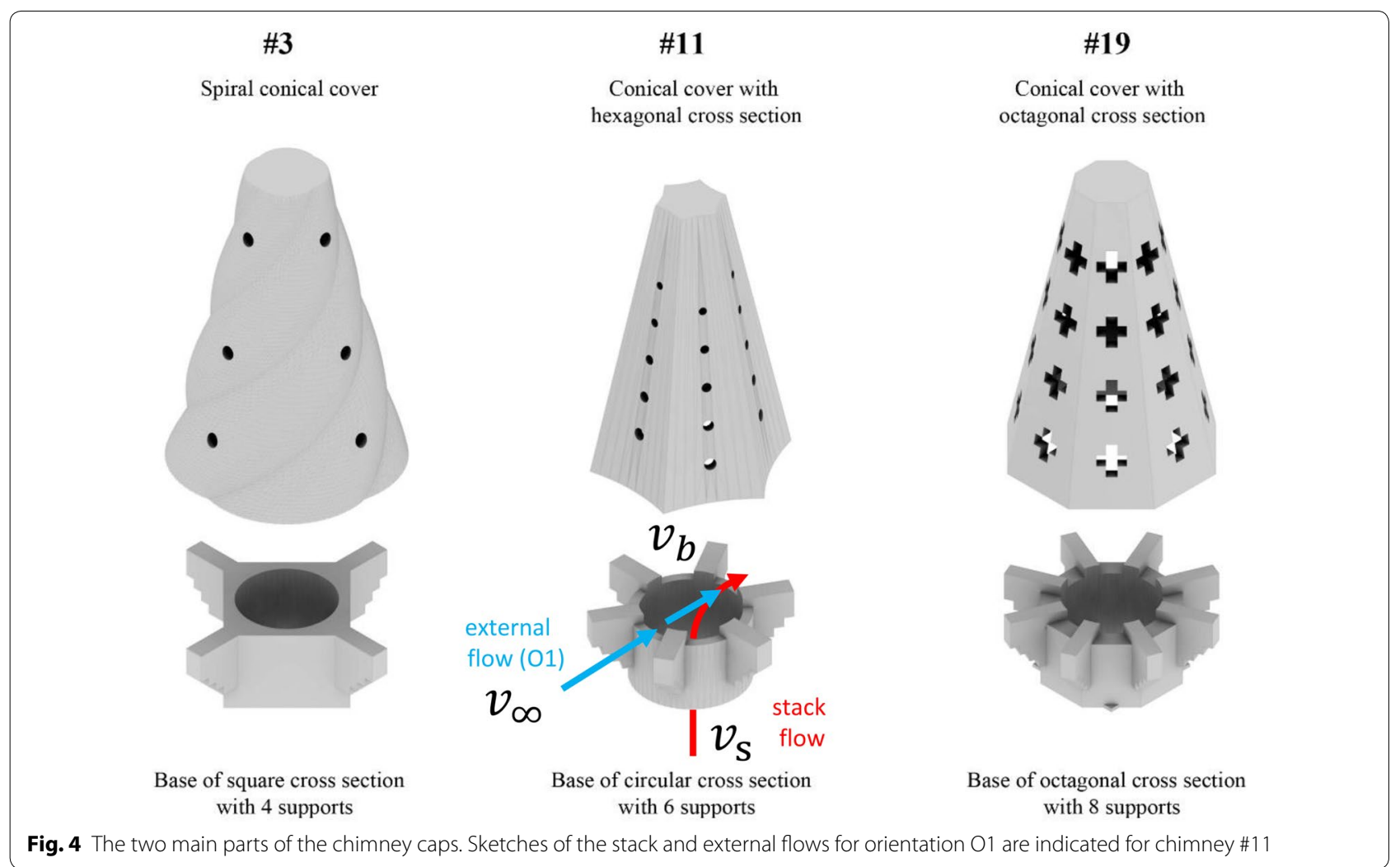


distributed along the diagonals of a regular hexagon. The base of chimney cap \#19 has 8 supports along the diagonals of a regular octagon and 8 vertical symmetry planes. Considering these symmetry planes, the two different orientations of the external velocity considered correspond to two parallel directions of two consecutive vertical symmetry planes of the base of the chimneys. One orientation (denoted as O1) of the external flow is aligned towards the midpoint between two consecutive supports and the other $(\mathrm{O} 2)$ is aligned with one of the supports.

As shown in Fig. 3 there are some models in which the supports elevate the cover above the top part of the base. Particularly models \#1, \#2, \#4, \#6, \#7, \#8, \#11 and \#19 have this feature, while in the rest of the models the bottom part of the cover is at the same level as the top part of the base section. Figure 4 illustrates this feature for chimneys \#3, \#11 and \#19. It can be seen in this figure that the supports of chimneys \#11 and \#19 elevate the cover above the bases while for chimney \#3 the top part of the supports is at the same level as the top part of the base. It is worth noting that for the models in which the cover is at the same level as the top part of the cylindrical bottom there is an opening between the cover and the bottom base.

It can be seen in Fig. 3 that there is a wide variety of the covers, with different number of openings with different sizes and geometries. The horizontal internal cross section of the covers can be square (for chimneys \#1, \#2 and \#6), hexagonal (chimneys \#7, \#8,\#11,\#13), octagonal (chimney \#19) or circular (chimneys \#3, \#5, \#9, \#10 and \#14 to \#18).

\section{Model and discussion \\ Model and data reduction}

For each chimney model and each external flow orientation the measured pressure inside the stack pipe depends on the external flow velocity and the stack velocity. Smoke visualizations performed in some of the models showed that the upward flow in the stack is released out of the chimney through the bottom openings located between the top part of the base and the bottom part of the cover. In addition, smoke released in the external flow revealed that the external flow mainly entered the chimney cap through the openings between the supports located in the pressure side and left the chimney together with the stack flow through the openings located in the wake side. This flow arrangement is sketched for chimney \#11 in Fig. 4.

In order to build a simplified model of the suction capacity of each chimney cap we can consider the behavior of the external flow entering the chimney cap through the openings between the supports. The application of the Bernoulli equation along a streamline of the external flow that enters the base of the chimney through an opening between two consecutive supports (see sketch in Fig. 4 for chimney\#11) can be written as

$$
P_{b}=\frac{\rho}{2}\left(v_{\infty}^{2}-v_{b}^{2}\right)
$$

In Eq. $1, P_{b}$ is the relative pressure inside the base of the chimney (which is measured with the pitot tube), $v_{\infty}$ is the external uniform wind velocity at atmospheric pressure $\left(P_{\infty}=0\right)$, and $v_{b}$ is the velocity of the external flow inside the base of the chimney, which is at a pressure $P_{b}$. As indicated in Fig. 4 the external flow enters the base through one of the openings at velocity $v_{b}$. Note that Eq. 1 assumes isothermal, incompressible, steady flow and neglects friction effects. In general, to create suction (i.e. $P_{b}<0$ ) the external flow inside the chimney has to accelerate $v_{b}>v_{\infty}$ producing the Venturi effect. We can define the parameter $K$ as

$$
v_{b}=K v_{\infty}
$$

(i.e. the ratio between the velocity inside the base of the chimney cap, $v_{b}$, and the external flow velocity, $v_{\infty}$ ).

The introduction of Eq. 2 into Eq. 1 leads to

$$
P_{b}=\frac{1}{2} \rho v_{\infty}^{2}\left(1-K^{2}\right)
$$

As shown in Fig. 4 the stack flow velocity corresponds to the velocity inside the stack pipe. This velocity and the pressure at this location are measured with the pitot tube. In contrast, the velocity in the base of the chimney corresponds to the velocity of the external flow entered through one of the openings of the chimney base located above the stack pipe. Dividing Eq. 3 by the dynamic pressure associated with the stack flow velocity $\left(\frac{1}{2} \rho v_{s}^{2}\right)$ one can get the nondimensional equation that relates the pressure coefficient $\left(C_{p}\right)$ and the velocity ratio $\left(v_{\infty} / v_{s}\right)$

$$
C_{p}=\frac{P_{b}}{\frac{1}{2} \rho v_{s}^{2}}=\left(1-K^{2}\right)\left(\frac{v_{\infty}}{v_{s}}\right)^{2}
$$

Equation 4 indicates that, under the above hypotheses, the pressure coefficient has a quadratic dependency on the velocity ratio $v_{r}=v_{\infty} / v_{s}$. The coefficient of the parabola, $\left(1-K^{2}\right)$, is related with the acceleration of the external flow inside the chimney. Note that if $v_{b}>v_{\infty}$, $(K>1)$ the coefficient of the parabola is negative and the pressure inside the stack tube is negative, favoring the suction flow from the stack. In contrary if $v_{b}<v_{\infty}$ Eq. 4 predicts a pressure inside the stack pipe larger than the ambient pressure. This situation can lead to a malfunction of the chimney inducing external flow towards the stack pipe. 


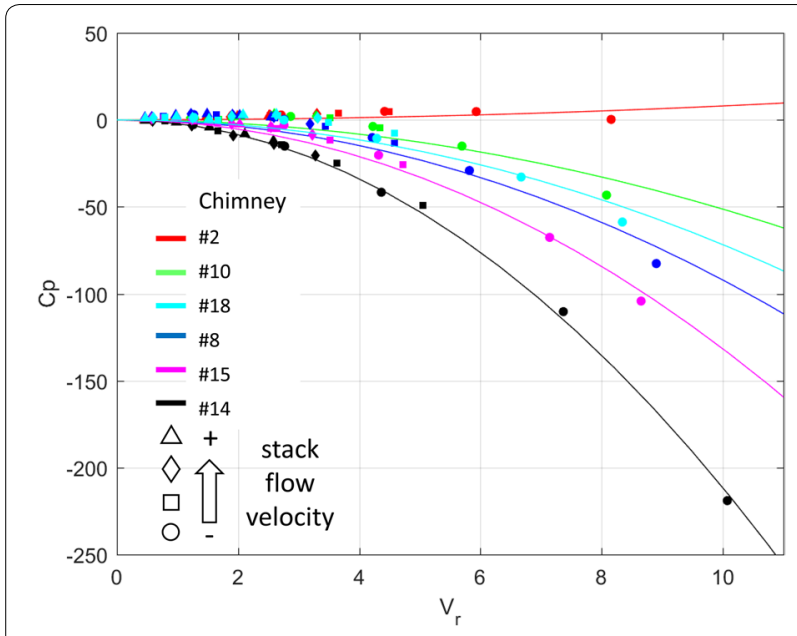

Fig. 5 Measured pressure coefficient $\left(C_{p}=P_{b} / \frac{1}{2} \rho v_{s}^{2}\right)$, defined in Eq. 4 , as a function of the velocity ratio $\left(v_{r}=v_{\infty} / v_{s}\right)$ for chimneys $\# 2$, $\# 8, \# 10, \# 14, \# 15$ and \#18 for the orientation O2. Different stack velocities are plotted with different symbols. Lines are least square fittings of the measured data for each chimney to a parabola of the form $y=a x^{2}$

\section{Chimneys performance}

Figure 5 shows, as an example, the measured pressure coefficient (Eq. 4) as a function of the velocity ratio for a selected set of chimneys and different combinations of stack velocities, which are plotted with different symbols. Note that not all the data, corresponding to all the chimneys with the two orientations, has been plotted in this figure for clarity. In Fig. 5, lines correspond to the minimum squared differences fittings of the measured data to parabolas of the form $y=a x^{2}$. It can be seen that Eq. 4, which is of the same analytical form, fits well the measurements plotted in Fig. 5. This indicates that the model gives the correct scaling of the velocities and the pressure inside the stack pipe. It can be seen in Fig. 5 that, except for chimney \#2, the set of experimental conditions generates negative relative pressure in the stack pipe (i.e. $K>1$ ). For the models plotted in Fig. 5, chimney \#14 shows the best performance with relatively large negative values of the pressure coefficient. In contrary chimney \#2 exhibits small, positive, pressure coefficients which are essentially independent of the magnitude of the velocity ratio.

Table 1 shows the determination factors $\left(R^{2}\right)$ and the corresponding values of the coefficients of the parabolas of the fittings for the 19 models under the two different orientations of the external flow considered. Except for chimneys \#2, \#3 and \#7 under the orientation $\mathrm{O} 2$, the model derived in the previous subsection, based on the potential flow theory, explains reasonably well the measured pressure decrement inside the chimneys. The cases
Table 1 Fitting parameters for the 19 chimneys

\begin{tabular}{|c|c|c|c|c|}
\hline $\begin{array}{l}\text { Chimney } \\
\text { number }\end{array}$ & Orientation & $\left(1-K^{2}\right)$ & $K$ & $R^{2}$ \\
\hline \multirow[t]{2}{*}{1} & 01 & -1.97 & 1.72 & 0.996 \\
\hline & $\mathrm{O} 2$ & 0.44 & 0.75 & 0.930 \\
\hline \multirow[t]{2}{*}{2} & $\mathrm{O} 1$ & -1.82 & 1.68 & 0.994 \\
\hline & $\mathrm{O} 2$ & 0.01 & 0.99 & $<0$ \\
\hline \multirow[t]{2}{*}{3} & $\mathrm{O} 1$ & -1.67 & 1.64 & 0.991 \\
\hline & $\mathrm{O} 2$ & -0.13 & 1.06 & $<0$ \\
\hline \multirow[t]{2}{*}{4} & $\mathrm{O} 1$ & -1.69 & 1.64 & 0.999 \\
\hline & $\mathrm{O} 2$ & -0.12 & 1.06 & 0.816 \\
\hline \multirow[t]{2}{*}{5} & 01 & -2.00 & 1.73 & 0.997 \\
\hline & $\mathrm{O} 2$ & -0.95 & 1.40 & 0.975 \\
\hline \multirow[t]{2}{*}{6} & $\mathrm{O} 1$ & -2.31 & 1.82 & 0.998 \\
\hline & $\mathrm{O} 2$ & -0.78 & 1.33 & 0.983 \\
\hline \multirow[t]{2}{*}{7} & 01 & -0.29 & 1.13 & 0.954 \\
\hline & $\mathrm{O} 2$ & -0.02 & 1.01 & $<0$ \\
\hline \multirow[t]{2}{*}{8} & $\mathrm{O} 1$ & -0.49 & 1.22 & 0.974 \\
\hline & $\mathrm{O} 2$ & -1.05 & 1.43 & 0.958 \\
\hline \multirow[t]{2}{*}{9} & $\mathrm{O} 1$ & -1.00 & 1.41 & 0.989 \\
\hline & $\mathrm{O} 2$ & -0.61 & 1.27 & 0.853 \\
\hline \multirow[t]{2}{*}{10} & $\mathrm{O} 1$ & -1.04 & 1.43 & 0.985 \\
\hline & $\mathrm{O} 2$ & -0.61 & 1.27 & 0.922 \\
\hline \multirow[t]{2}{*}{11} & $\mathrm{O} 1$ & -0.87 & 1.37 & 0.965 \\
\hline & $\mathrm{O} 2$ & -1.30 & 1.52 & 0.991 \\
\hline \multirow[t]{2}{*}{12} & $\mathrm{O} 1$ & -1.24 & 1.50 & 0.987 \\
\hline & $\mathrm{O} 2$ & -0.94 & 1.39 & 0.991 \\
\hline \multirow[t]{2}{*}{13} & $\mathrm{O} 1$ & -1.10 & 1.45 & 0.981 \\
\hline & $\mathrm{O} 2$ & -0.91 & 1.38 & 0.962 \\
\hline \multirow[t]{2}{*}{14} & $\mathrm{O} 1$ & -1.08 & 1.44 & 0.999 \\
\hline & $\mathrm{O} 2$ & -1.92 & 1.71 & 0.998 \\
\hline \multirow[t]{2}{*}{15} & 01 & -1.00 & 1.42 & 0.997 \\
\hline & $\mathrm{O} 2$ & -1.46 & 1.57 & 0.989 \\
\hline \multirow[t]{2}{*}{16} & O1 & -1.31 & 1.52 & 0.963 \\
\hline & $\mathrm{O} 2$ & -1.50 & 1.58 & 0.993 \\
\hline \multirow[t]{2}{*}{17} & O1 & -1.49 & 1.58 & 0.999 \\
\hline & $\mathrm{O} 2$ & -1.35 & 1.53 & 0.991 \\
\hline \multirow[t]{2}{*}{18} & O1 & -1.68 & 1.64 & 0.998 \\
\hline & $\mathrm{O} 2$ & -2.06 & 1.75 & 0.999 \\
\hline \multirow[t]{2}{*}{19} & 01 & -1.58 & 1.61 & 0.999 \\
\hline & $\mathrm{O} 2$ & -1.73 & 1.65 & 0.999 \\
\hline
\end{tabular}

in which a negative determination factor is obtained (chimneys \#2, \#3 and \#7 with orientation O2) correspond to values of the parameter $K$ smaller than or very close to 1 . In these cases, as shown for chimney \#2 in Fig. 5, the pressure coefficient is essentially independent of the velocity ratio.

Figure 6 shows the parameter $K$ for each chimney under the two orientations of the external flow considered. The black line bar indicates for each chimney the 


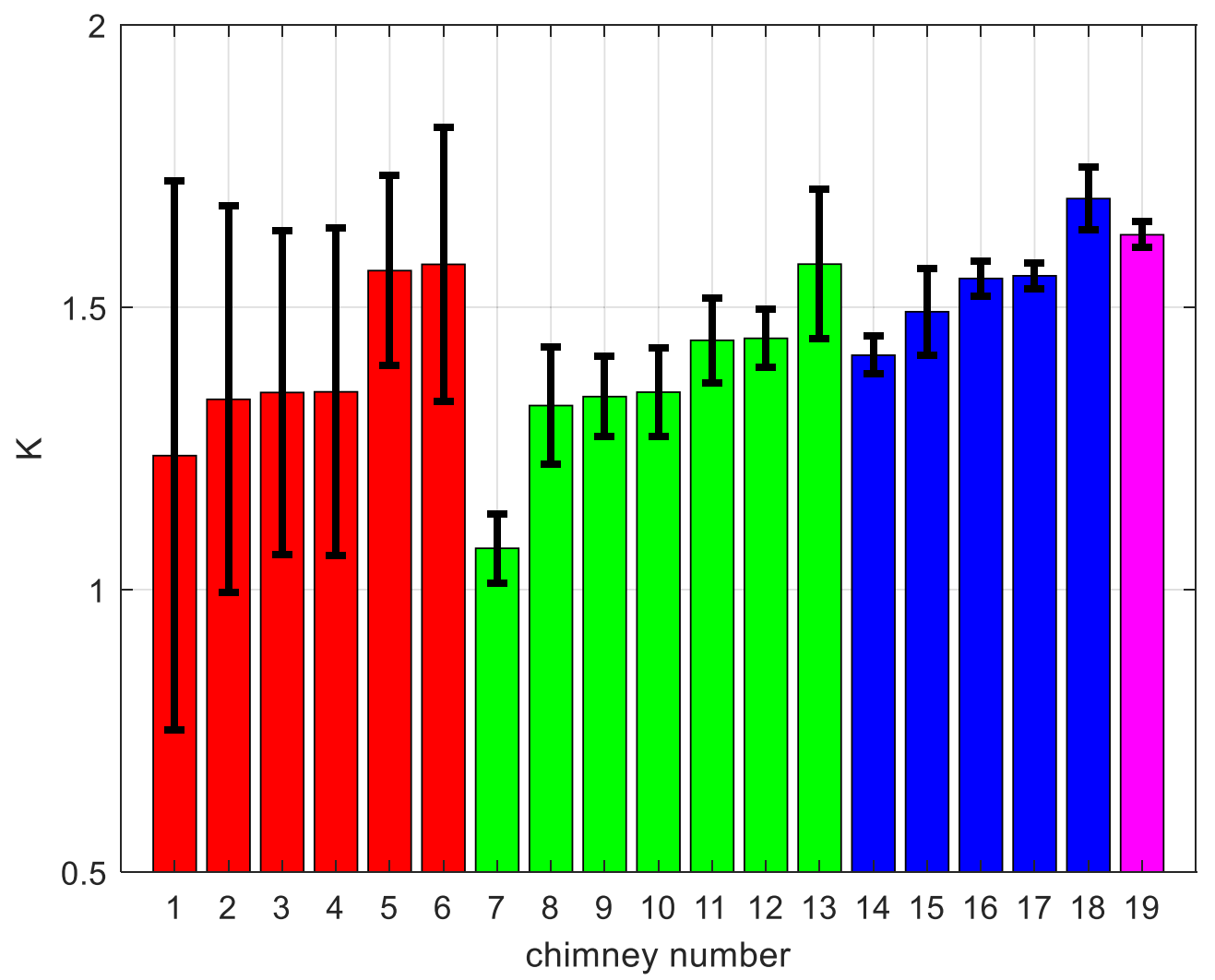

Fig. 6 Bar plot of the parameter $K$, defined in Eq. 2 as the ratio between the external flow velocity in the base of the chimney and the external wind velocity. The height of the colored bars corresponds to the average value of the two orientations. The black lines indicate the two values of $K$ for the two orientations, $\mathrm{O} 1$ and $\mathrm{O} 2$, shown in Fig. 3 with arrows

values of the two orientations and the height of the color bar corresponds to the averaged value of the two orientations. Note that, according to Eq. $4, K<1$ corresponds to positive pressures in the stack and $K>1$ to negative pressures.

We grouped the chimneys into 4 sets which are indicated with different colors in the bars of Fig. 6 and in the color bars below each chimney in Fig. 3. The first group, plotted in red in Fig. 6, is constituted by chimneys \#1 to \#6. These chimneys have four supports and exhibit a significant larger variability of the parameter $K$ depending on the orientation than the other chimneys. It can be seen in Table 1 that, for these chimneys, orientation $\mathrm{O} 1$ leads to a relatively large values of $K$, indicating that the external flow that enters the base of the chimney accelerates effectively thanks to the reduction of the available area for the flow, which is produced by the two consecutive supports which are at inclination of $90^{\circ}$ (see for example chimney \#3 in Fig. 4). In contrary the orientation $\mathrm{O} 2$, which corresponds to an external flow directed towards the alignment of one of the supports, produces very low values of $K$, especially in chimneys \#1 to \#4. In this case this orientation constrains the acceleration of the external flow into the base of the chimney, which is directed perpendicularly to the supports.

The second and third groups, plotted respectively in green and blue in Fig. 6, include the chimneys with six supports. It can be seen that the variability of the parameter $K$ for the two different orientations is smaller than for the chimneys with four supports. This indicates that these chimneys are more insensitive to the orientation of the external flow. We grouped the chimneys with six supports and with covers with a conical prismatic shape into group 2 (green in Fig. 6) and the chimneys with six supports and with covers with a conical cylindrical shape into group 3 (blue in Fig. 6). This geometrical difference of the covers can be observed in the top views of the chimneys of Fig. 3. Note that the hexahedral shape is evident in the top views of the chimneys of group 2, while the circular shape observed in the top views of the chimneys of group 3. It can be seen in Fig. 6 that the conical cylindrical shapes of the covers produce, in general, larger values of $K$ and smaller sensitivity to the orientation than the conical prismatic shapes. Finally Chimney \#19 has eight supports and has an octagonal prismatic 
cover and exhibits a relatively large value of the parameter $K$, plotted in magenta in Fig. 6, with a small variability with respect to the orientation of the external flow.

\section{Conclusions}

We examined the performance of the 19 ornamental chimney caps of the Palau Güell by analyzing experimentally, with wind tunnel measurements, the pressure decrement inside the stack pipe produced by the external flow. The chimneys exhibit a wide range of shapes and they have covers with different number of overtures with different geometries. However, they have two main parts in common: a base with a number of supports distributed symmetrically along the top part and a conical cover sustained by the supports.

We derived a simplified model (Eq. 4 and Fig. 5) based on the potential flow theory to relate the nondimensional pressure reduction in the stack with the ratio between the external and stack flow velocities. It has been found that the behavior of the chimneys predicted by this model is in agreement with the measurements. The model and the measurements indicate that the pressure coefficient, based on the relative pressure inside the stack, only depends on the ratio between the velocity of the external flow and the velocity in the stack pipe. The behavior of the chimneys can be classified (Fig. 6) considering the ratio $(K)$ between the velocity of the external flow that enters inside the base of the chimney cap and the velocity of the external flow outside the chimney.

The number and distribution of the supports of the base of the chimney is important because the external flow enters the base through the openings located between them. Six of the 19 chimneys have four supports and they exhibit good performance only if the external flow is directed towards the region between two consecutive supports. There are 12 chimneys with six supports and one with eight supports which show good performance independently of the orientation of the external flow. From this set of chimneys those with six supports and with a cover with a conical cylindrical shape and the chimney with eight supports exhibit larger performances independently of the orientation of the external flow.

This paper illustrates the procedures that can be used for the interpretation and analysis of aerodynamical features and ventilation strategies in heritage buildings. The workflow includes photogrammetry, 3D printing of scale models and wind tunnel experiments. In addition, the conclusions, obtained for this particular set of chimney caps, outlined above, can be useful for the design of chimney caps for ornamental and general use.

\section{Abbreviations}

CFD: computational fluid dynamics; PLA: polylactic acid; PVC: polyvinyl chloride; STL: standard tessellation language.

\section{Acknowledgements}

We would like to thank Diputació de Barcelona to facilitate the access to the roof of Palau Güell to take the pictures of the chimneys and for the permission to use the picture of the general view of the roof shown in Fig. 1.

\section{Authors' contributions}

AS have performed the photogrammetry of the chimneys. Jl have carried out the wind tunnel measurements. BH and JP have contributed to interpretation and written several sections. All authors co-conceived the study, participated in its design. All authors read and approved the final manuscript.

\section{Funding}

This study has been supported by projects DPI2016-75791-C2-1-P and 2017SGR-1234 granted by the Spanish Ministerio de Economía y Competitividad and Generalitat de Catalunya, respectively.

Availability of data and materials

The data is available within the article.

\section{Competing interests}

The authors declare that they have no competing interests.

\section{Author details}

${ }^{1}$ Escola Técnica Superior d'Arquitectura, Universitat Rovira i Virgili, 43204 Tarragona, Spain. ${ }^{2}$ Departament d'Enginyeria Mecànica, Universitat Rovira i Virgili, 43007 Tarragona, Spain. ${ }^{3}$ Departament d'Enginyeria Informàtica i Matemàtiques, Universitat Rovira i Virgili, 43007 Tarragona, Spain.

Received: 23 October 2019 Accepted: 22 December 2019

Published online: 06 January 2020

\section{References}

1. Etheridge D. Natural ventilation of buildings: theory, measurement and design. Hoboken: Wiley; 2011.

2. Allard F, Ghiaus $C$, editors. Natural ventilation in the urban environment: assessment and design. Abingdon: Routledge; 2012.

3. Gonzalez MA. On the aerodynamics of natural ventilators. Build Environ. 1984;19:179-89.

4. Farías O, Jara F, Betancourt R. Theoretical and experimental study of the natural draft in chimneys of buildings for domestic gas appliances. Energy Build. 2008;2008(40):756-62.

5. Khan N, Su Y, Riffat SB. A review on wind driven ventilation techniques. Energy Build. 2008;40:1586-604.

6. Lai CM. Experiments on the ventilation efficiency of turbine ventilators used for building and factory ventilation. Energy Build. 2003;35:927-32.

7. Lien STJ, Ahmed NA. Numerical simulation of rooftop ventilator flow. Build Environ. 2010;2010(45):1808-15.

8. Lowther AWG. Romano-British chimney-pots and finials. Antiq J. 1976;1976(56):35-48.

9. Simpson W. The architectural history of Huntly Castle. Proc Soc Antiq Scotl. 1992;56:134-63.

10. Bonet A. Las chimeneas de El Escorial. Revista Proyecto y Ciudad. 2018;9:5-16.

11. Shirzadi M, Tominaga Y, Mirzaei PA. Wind tunnel experiments on crossventilation flow of a generic sheltered building in urban areas. Build Environ. 2019:158:60-72.

12. Le Roux N, Faure X, Inard C, Soares S, Ricciardi L. Reduced-scale study of wind influence on mean airflows inside buildings equipped with ventilation systems. Build Environ. 2012;58:231-44.

13. Wong $\mathrm{NH}$, Heryanto $\mathrm{S}$. The study of active stack effect to enhance natural ventilation using wind tunnel and computational fluid dynamics (CFD) simulations. Energy Build. 2004:36:668-78.

14. Yang S, Alrawashdeh H, Zhang C, Qi D, Wang LL, Stathopoulos T. Wind effects on air curtain performance at building entrances. Build Environ. 2019;151:75-87. 
15. Calautit JK, Hughes BR. Wind tunnel and CFD study of the natural ventilation performance of a commercial multi-directional wind tower. Build Environ. 2014;80:71-83.

16. Montazeri $\mathrm{H}$. Experimental and numerical study on natural ventilation performance of various multi-opening wind catchers. Build Environ. 2011;46:370-8.

17. Chen W, Liu J, Mak CM, Wang P, Zhao L, Wong HM. Near fields of annular slotted hoods measured via 2D-PIV. Build Environ. 2018;144:1-8.

18. Kosutova K, van Hooff T, Vanderwel C, Blocken B, Hensen J. Cross-ventilation in a generic isolated building equipped with louvers: wind-tunnel experiments and CFD simulations. Build Environ. 2019;154:263-80.

19. Shao M, Li L, Wang S, Wang E, Li Z. Deterioration mechanisms of building materials of Jiaohe ruins in China. J Cult Herit. 2013;14:38-44.

20. Grau-Bové J, Mazzei L, Strlic M, Cassar M. Fluid simulations in heritage science. Herit Sci. 2019;7:16.

21. Requena-Ruiz I. Thermal comfort in twentieth-century architectural heritage: two houses of Le Corbusier and André Wogenscky. Front Architect Res. 2016;5:157-70.

22. Corgnati SP, Perino M. CFD application to optimise the ventilation strategy of Senate Room at Palazzo Madama in Turin (Italy). J Cult Herit. 2013;14:62-9.

23. Balocco C, Grazzini G. Numerical simulation of ancient natural ventilation systems of historical buildings. A case study in Palermo. J Cult Herit. 2009;10:313-8.

24. Balocco C. Daily natural heat convection in a historical hall. J Cult Herit. 2007:8:370-6
25. Malaurent P, Brunet J, Lacanette D, Caltagirone JP. Contribution of numerical modelling of environmental parameters to the conservation of prehistoric cave paintings: the example of Lascaux Cave. Conserv Manag Archaeol Sites. 2006;8:59-76.

26. Albero S, Giavarini C, Santarelli ML, Vodret A. CFD modeling for the conservation of the Gilded Vault Hall in the Domus Aurea. J Cult Herit. 2004;5:197-203.

27. Aydin YC, Mirzaei PA. Wind-driven ventilation improvement with plan typology alteration: a CFD case study of traditional Turkish architecture. Build Simul. 2017;10:239-54

28. Hussein AS, El-Shishiny H. Wind flow modeling and simulation over the Giza Plateau cultural heritage site in Egypt. ACM J Comput Cult Herit. 2009:2:6-22.

29. González A, Carbó P. La azotea fantástica. La cubierta del Palau Güell. Informes de la Construcción. 1990;42:31-41.

30. González A, Lacuesta R, Baldomà M El. Palacio Güell: Una obra maestra de Antoni Gaudí. Barcelona: Diputació de Barcelona; 2013.

31. Tourn S, Pallares J, Cuesta I, Paulsen US. Characterization of a new open jet wind tunnel to optimize and test vertical axis wind turbines. J Renew Sust Energy. 2017;9:33302.

\section{Publisher's Note}

Springer Nature remains neutral with regard to jurisdictional claims in published maps and institutional affiliations.

\section{Submit your manuscript to a SpringerOpen ${ }^{\circ}$ journal and benefit from:}

- Convenient online submission

- Rigorous peer review

- Open access: articles freely available online

- High visibility within the field

- Retaining the copyright to your article

Submit your next manuscript at $\boldsymbol{\nabla}$ springeropen.com 